\title{
The Value Of Graduate Certificate Programs In Engineering Education: A Strategic Assessment
}

Susan L. Murray, Ph.D., Missouri University of Science and Technology, USA Suzanna K. Long, Ph.D., Missouri University of Science and Technology, USA Cassandra C. Elrod, Ph.D., Missouri University of Science \& Technology, USA Susmitha Akula, M.S., Missouri University of Science and Technology, USA

\begin{abstract}
There has been a significant increase in the popularity of non-degree graduate certificates throughout the past decade. This increase has raised questions about the value of engineering graduate certificate programs from students, alumni, and employers. Do engineering certificate programs provide real world skills and knowledge? Do they serve as effective recruiting tools for universities? Do they provide opportunities for students to meet their professional goals in terms of salary increase and promotions? This study explores these questions. Eighty-three current and former engineering certificate students, as well as forty professionals from industry, were surveyed about their value perception of graduate certificate programs. Guidance for engineering educators and other professionals concerned with development and marketing of engineering graduate certificate programs is also presented.
\end{abstract}

Keywords: Graduate Certificate Programs (GCPs); distance education; engineering education

\section{INTRODUCTION}

raduate certificate programs (GCPs) have grown in popularity over the past decade; however, limited research has been done on the value of GCPs for stakeholders: students, alumni, and industry. A case study is used in this paper to explore whether GCPs are an effective recruiting tool for universities. Survey and enrollment data was obtained to determine how many students completed GCPs and followed with enrollment in master's degrees or other degree programs. The second objective of this study is to discover if the GCPs provide opportunities for students to meet their professional goals in terms of salary increase and promotions. Furthermore, students and alumni perceptions were compared to understand the expectations and actual benefits of the GCPs.

\section{LITERATURE REVIEW}

A certificate program is an educational program that results in a certificate of completion rather than a degree. These programs educate students in a specific area or specialty. Certificate programs are often seen as an important step in enhancing one's knowledge quickly. Certificate programs are not only for those who wish to upgrade their skills, but are also useful to assist in a career shift or promotion. In the United States, certification has become recognized in the majority of professions. The earliest were created during the 1930s and 1940s, and represented recognizable careers options (Jaffeson, 2004). According to the Department of Education's Integrated Post Secondary Data System (IPEDS), there are over 2,000 post baccalaureate certificate programs. The growth of certificate programs occurs in multiple streams. "Although there is no systematic count of those offered by organizations outside the academy, just look on the business cards of financial planners, brokers, insurance and tax consultants, architects, nurse practitioners, therapists, social workers, medical doctors, health-care administrators, systems engineers, manufacturing resource and production managers, and specialists in new industries and you will get an intuitive read of the increasing currency and popularity of certification" (Irby, 1999). The market for certificates has been estimated at 40-50 million people, but it is difficult to determine how many are awarded outside mainstream institutions (Kerka, 2000). 
Certificate programs are designed to provide a competitive advantage in the market. Certificates can serve as a detached objective or supplement full degree programs. This is particularly true for professionals with time or financial limitations. Completing certificate programs is becoming more feasible as many universities offer certificate programs in fields such as business, education, health care, and technology (Irby, 1999). Certificate programs offer flexibility not only to the students, but universities as well. Unlike degree programs, certificates require far less bureaucratic red tape often seen in university settings. Schools and departments retain a good deal of autonomy in their implementation of these programs and obtain a substantial revenue stream (Tibbo, 2006). Traditionally, certificate programs offered by universities across the nation are structured with face-to-face classes; however, the majority offer or are planning classes online. Since there is no degree track, students can often directly enroll for the program of their choice.

A report by the National Center for Education Statistics presents information about distance education degree and certificate programs in Title IV postsecondary institutions by institutional type, level of the degree and certificate programs, and general field of study (NCES 2006-2007). A striking number of certificate programs have been designed to be completed via distance education, according to NCES. Some key findings from the report include:

- $\quad$ During the 2006-07 academic year, two-thirds (66 percent) of 2-year and 4-year Title IV degree granting postsecondary institutions reported offering online, hybrid/blended online, or other distance education courses for any level or audience. Sixty-five percent of the institutions reported college-level creditgranting distance education courses, and 23 percent of the institutions reported noncredit distance education courses.

- $\quad$ Twenty-nine percent of 2-year and 4-year institutions reported degree programs and 17 percent reported certificate programs that were designed to be completed totally through distance education.

- $\quad$ Of the estimated 11,200 college-level programs that were designed to be completed totally through distance education in 2006-07, 66 percent were reported as degree programs while the remaining 34 percent were reported as certificate programs.

- $\quad$ The most common factors cited as affecting distance education decisions were meeting student demand for flexible schedules (68 percent), providing access to college for students who would otherwise not have access (67 percent), making more courses available (46 percent), and seeking to increase student enrollment (45 percent).

Charlton, Machin \& Clough (2000) list factors to consider in designing and implementing quality certificate programs including:

- $\quad$ Creating courses based on the strengths of the university to allow maximum resources available to students

- $\quad$ Conduct courses in association with agencies so that students are in touch with the real world while doing the certificate course

- $\quad$ Curriculum that satisfies course and industry requirements

- Management of direct and indirect costs related to educational activities in order for the programs to become self-sustaining

Universities can benefit from graduate certificate programs by recruiting new graduate students into their degree programs. Certificates can act as experiments for working students who have been out of school for years and wish get back into the academic setting. Students can "try out" graduate study as a non-degree student to see if they can successfully compete with full time graduate students (Daughton, 2007). Certificate programs may serve as a training opportunity or a stepping stone for a return to academics for adult learners. This determines those who are able, and signals those who are not quite ready, prior to launching an extensive and costly degree-program effort (Donovan, 1998).

A research study at an urban community college concluded that the effectiveness of occupational-technical certificate programs can be evaluated by means other than measuring the percentage of students who receive certificates of completion (Lohman, 2003). This study illustrates that program effectiveness can be measured by meeting career goals. 
Evaluating any degree program raises various questions. The following are important issues to consider:

- "What are the fundamental motivations of learners in the program?"

- "What do learners see as the strengths of the program?" and

- "What are learners' areas of concern about the program?"

This type of questioning is important because satisfied students are more likely to perform well, graduate, benefit, and encourage others to enroll (Cannon, Umble, Steckler \& Shay, 2001). In evaluating a program the stakeholders' purposes, ambitions, and/or aspirations should be considered.

\section{GRADUATE CERTIFICATE PROGRAM CASE STUDY}

A case study to evaluate GCPs was conducted at Missouri University of Science and Technology (Missouri $\mathrm{S} \& \mathrm{~T}$ ). The university provides both distance education and graduate certificates to a wide array of students (Evans, Murray, Daily, and Hall, 2000). Distance education at the university (previously known the University of Missouri Rolla) was started through the campus's Video Communications Center in 1985 in collaboration with the National Technological University (NTU). Established in 1984, NTU was one of the first accredited "virtual" universities to provide distance education to students nationwide. In 1994, Missouri S\&T and the United States Army began a program of intensive study taught by university faculty at a local Army facility that allowed officers to earn university graduate credit leading to a certificate in military construction management, followed by a Master's of Engineering Management and Systems Engineering (EMSE). The first group of students completed this program in the spring semester of 1995, and since its inception, over 1,000 officers have earned a Master's in engineering management through this program (Daughton, 2007). Different GCPs offered in the Department of Engineering Management and Systems Engineering at the Missouri University of Science and Technology are given in Table 1.

Table 1. List Of Graduate Certificates Offered In EMSE
\begin{tabular}{|l|}
\hline \multicolumn{1}{|c|}{ Graduate Certificate Title } \\
\hline Engineering Management \\
\hline Financial Engineering \\
\hline Human Systems Integration \\
\hline Leadership in Engineering Organizations \\
\hline Lean Six Sigma \\
\hline Military Construction Management \\
\hline Network Centric \\
\hline Project Management \\
\hline Quality Engineering \\
\hline Systems Engineering \\
\hline
\end{tabular}

\section{METHODOLOGY}

Students and alumni from the largest certificate granting departments, Engineering Management and Systems Engineering, were surveyed to gain their perspective on the experience they had in a GCP and how it benefited their career. The industrial cohort includes employers of EMSE graduates from various companies and Engineering Management Academy members who represent successful alumni who graduated over 20 years prior. Three online questionnaires were designed to obtain both quantitative and qualitative responses from the three stakeholder groups - students, alumni, and industry. Research on the use of traditional paper-based questionnaire in comparison to online questionnaire specifies that there are no major differences between the techniques and results that are used to assess. The latter method is more cost-efficient, reduces data entry errors, and increases survey accessibility (Miller, 2002). Most items on the questionnaires used a five-point Likert scale. The survey was also reviewed by the Missouri S\&T Institutional Review Board (IRB) prior to distribution to ensure all informed consent requirements were met.

The three stakeholder cohorts have different vantage points. The current students are generally anticipating the benefits of a GCP as opposed to the program graduates who maybe better able to judge the actual benefits of the certificates. All of the student participants have professional work experience, whether they were enrolled at the 
time of the survey or not. The industrial cohort illustrates the perceived GPC value from people who likely do not have a graduate certificate.

Chi-square tests for homogeneity were used to find the answer for the important research question - "Do all the stakeholders involved agree on the value of the GCPs?" All the chi-square tests were performed using Microsoft Excel software and the results were verified in Minitab software. Contingency tables and chi-square test of homogeneity were used to analyze the categorical data obtained. The test statistic $\left(\chi^{2}\right)$ is a function of the difference between observed values and expected values, which is compared to the chi-squared distribution (Dowdy \& Wearden, 1991). The null hypothesis $\left(\mathrm{H}_{\mathrm{o}}\right)$ was that stakeholders share a positive perception of value in regards to GCPs; it was assumed students, alumni, and industry clearly sees the advantages of GCPs. Chi-square tests were then performed for various combinations of stakeholders.

\section{RESULTS}

Of the 160 questionnaires deployed to EMSE graduate certificate students, 41 yielded useable results ( $25.6 \%$ response rate). There were 40 useable responses for both the alumni and industry groups. Table 2 presented areas of current interest in the graduate certificate programs offered by EMSE. Clearly, systems engineering and project management are popular topics of study for a graduate certificate.

Table 2. Current Student Participants Pursuing Different EMSE GCPs

\begin{tabular}{|c|c|c|c|c|c|}
\hline $\begin{array}{c}\text { Engineering } \\
\text { Management }\end{array}$ & $\begin{array}{c}\text { Financial } \\
\text { Engineering }\end{array}$ & $\begin{array}{c}\text { Military } \\
\text { Construction } \\
\text { Management }\end{array}$ & $\begin{array}{c}\text { Project } \\
\text { Management }\end{array}$ & $\begin{array}{c}\text { Network } \\
\text { Centric }\end{array}$ & $\begin{array}{c}\text { Systems } \\
\text { Engineering }\end{array}$ \\
\hline 9 & 3 & 2 & 12 & 1 & 14 \\
\hline
\end{tabular}

Of the 41 student survey participants 28 were distance students and three were on-campus students. The majority of students surveyed were reimbursed for tuition by their employers. All students who participated in the survey are domestic students. The distribution of student research participations mirrored the overall distribution of students with respect to specific certificate program and gender. Figures 1 and 2 illustrate the age and professional experience of respondents.

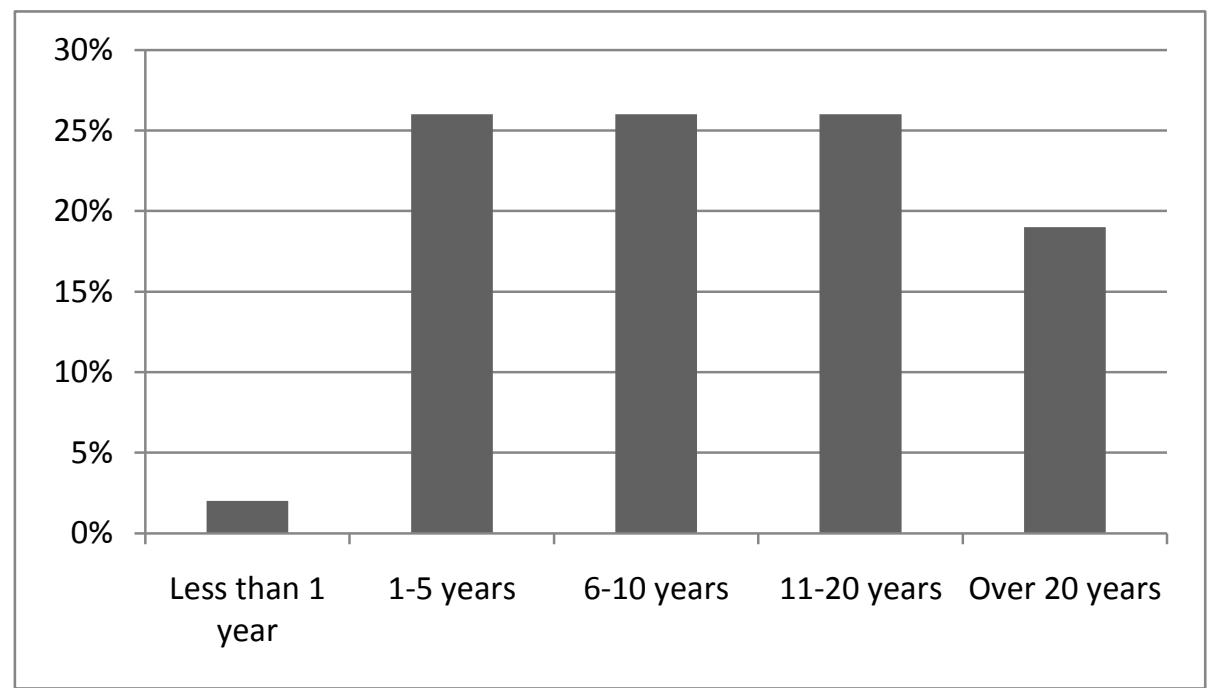

Figure 1. Professional Work Experience Of Students Before Enrolling Into EMSE GCPs 


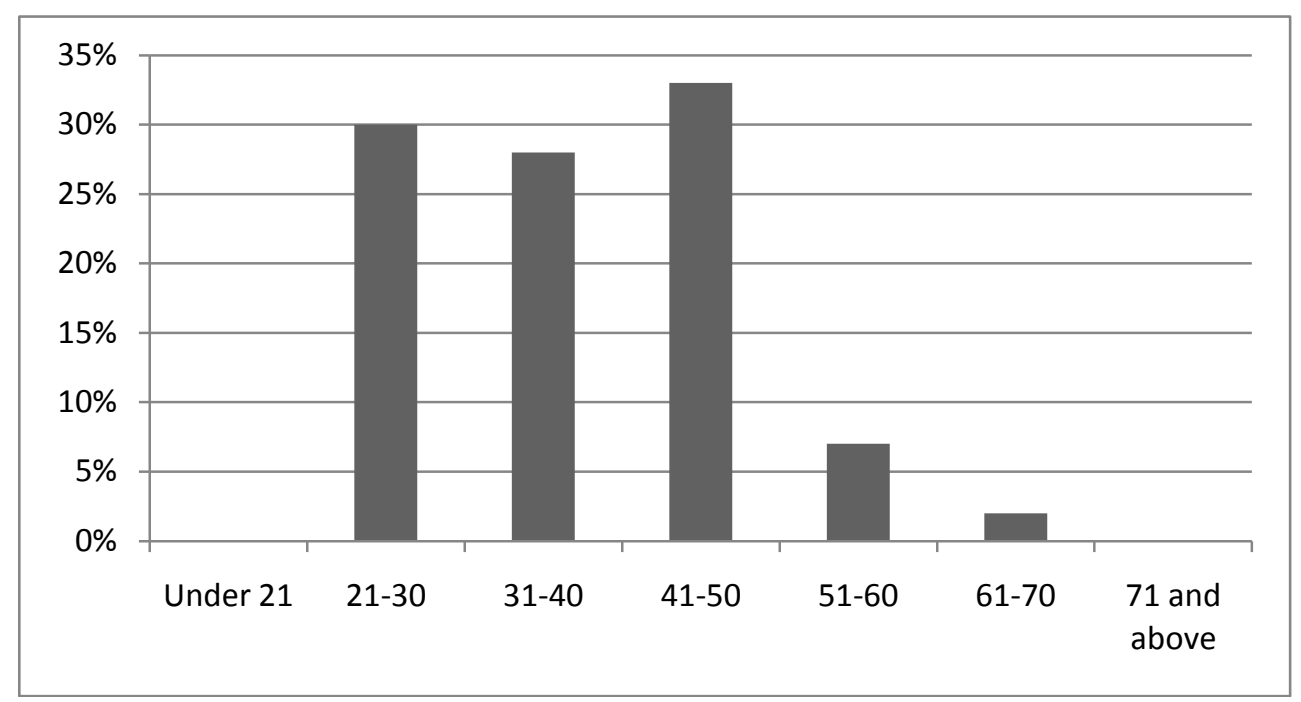

Figure 2. Student Participant Age Groups

A second, similar, questionnaire was sent to alumni of the GCPs. Details of these respondents are shown in Figure 3.

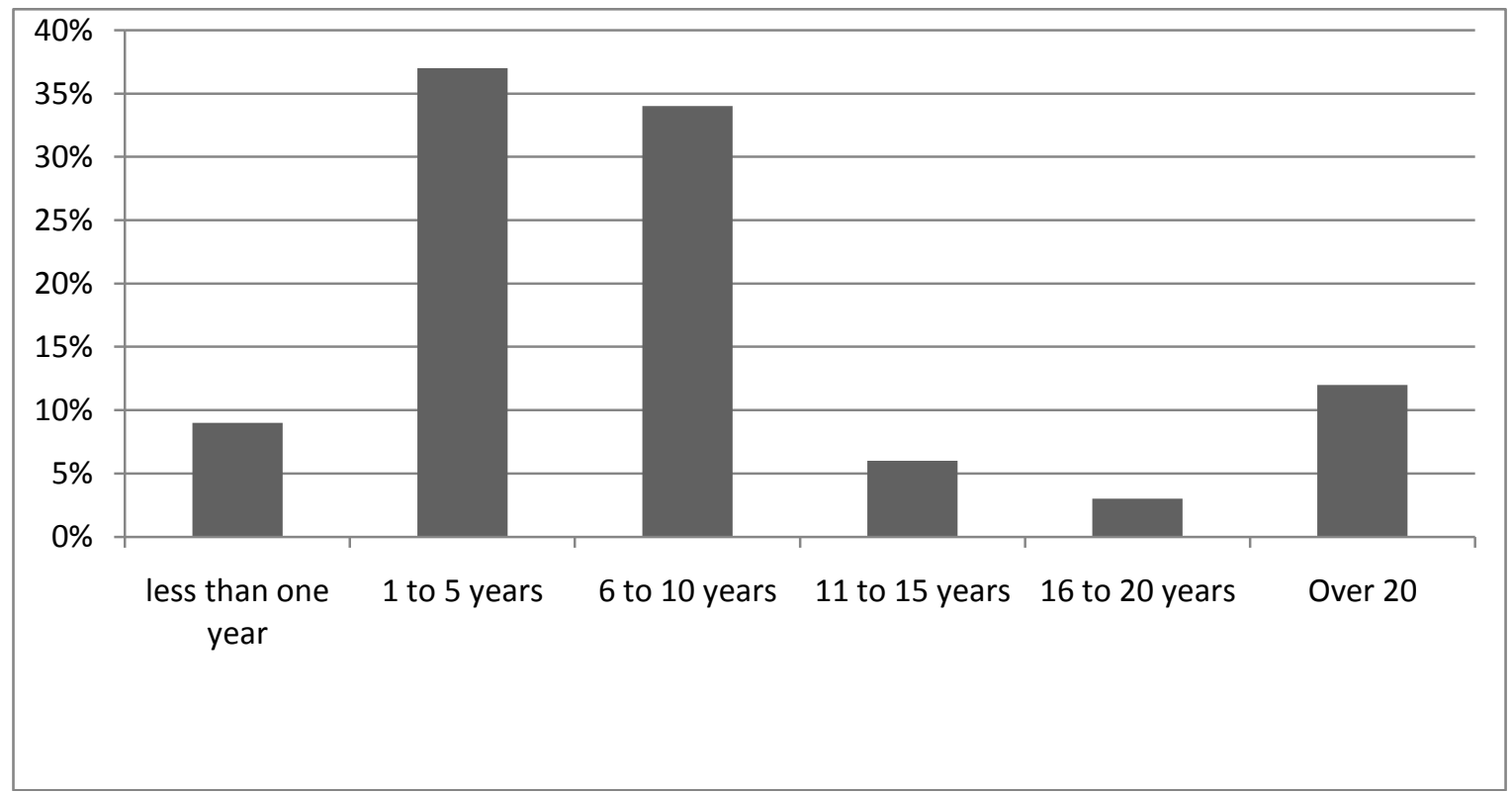

Figure 3. EMSE GCP Graduates' Professional Work Experience At Time Of The Survey

\section{Stakeholder Perceptions Of GCP Value}

One of the key research objectives of this study was to investigate the perceptions of the stakeholder groups regarding the value of the GCP's offered. The three stakeholder groups involved were asked to rate the value of the GCPs on a scale of one to five. The ratings given by the three stakeholder groups are displayed in Table 3. 
Table 3. Perception Of Certificate Value

\begin{tabular}{|c|c|c|c|c|c|c|c|}
\hline & Poor & Average & Good & Very Good & Excellent & Don't Know & Total \\
\hline Students & 0 & 1 & 7 & 20 & 14 & 0 & 42 \\
\hline Alumni & 0 & 0 & 6 & 18 & 14 & 0 & 38 \\
\hline Industry & 1 & 1 & 7 & 3 & 2 & 25 & 39 \\
\hline & 1 & 2 & 20 & 41 & 30 & 25 & 119 \\
\hline
\end{tabular}

The participant perceptions were statistically different, $\chi^{2}(3, \mathrm{~N}=199)=41.29, \mathrm{p}<0.05$; the three groups do not agree on the value of a GCPs. The alumni and student groups agreed that GCPs have added value. Chi-square testing showed that the third group, the industrial cohort, had a different view on the value of a GCP. A review of Table 3 shows that over $80 \%$ of the current or past students rated the GCPs as "very good" or "excellent" and only $13 \%$ of industry participants felt that the programs were "very good" or "excellent".

\section{Student Perceptions}

The survey also explored if the GCP were a path to a MS degree. In the student questionnaire $93 \%$ of the students said that they would return to Missouri S\&T for their Master's degree. 95\% of the alumni had enrolled to pursue their master's at Missouri S\&T since completing the GCP. Students were asked their reasons for selecting the university for a GCP and their responses are given in Figure 4. These survey results showed that GCPs are serving as a pathway to graduate degrees.

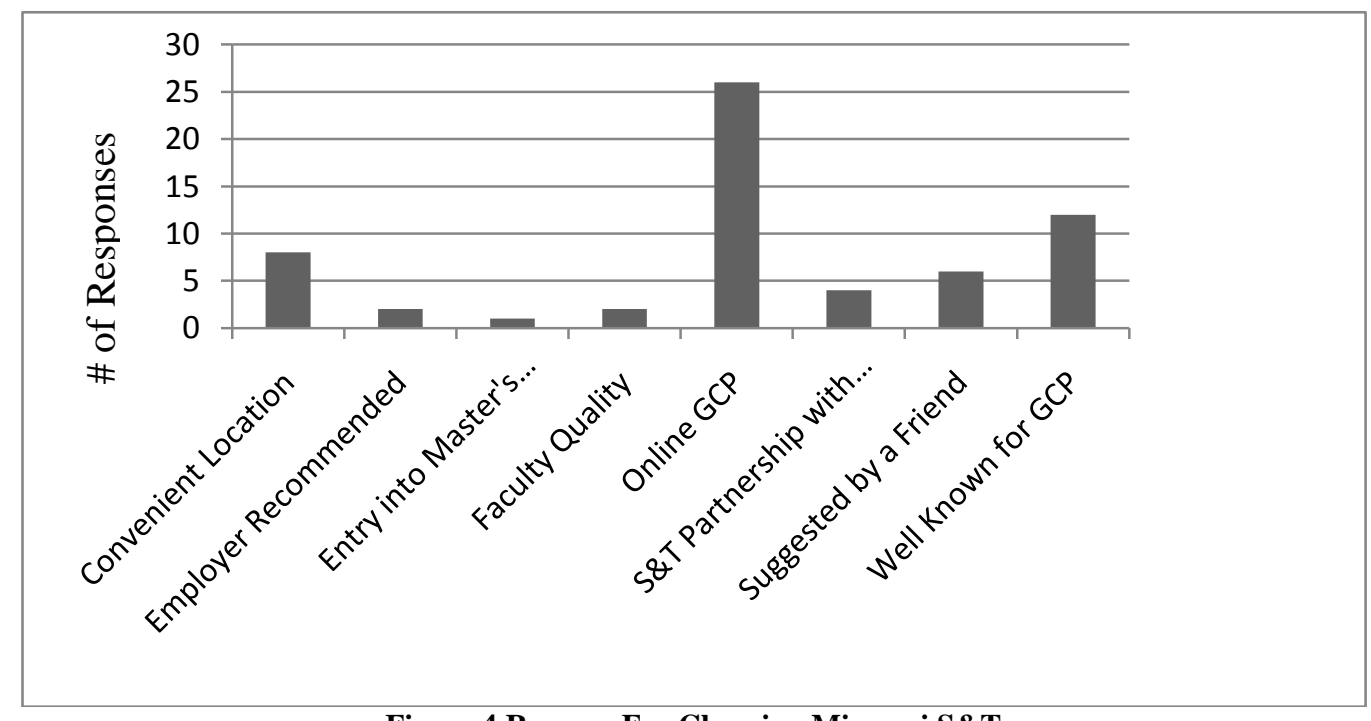

Figure 4 Reasons For Choosing Missouri S\&T

Student participants were also asked if they felt the need for other courses that could be included in the graduate certificate programs. Eleven participants (26\%) said that there is no need for new courses while 26 students (60\%) did not know if there is a need for any new courses, three suggested specific engineering courses to be added to the graduate certificate programs. Two suggested topic areas of "requirements development" and "people skills" as beneficial additions to their existing program.

\section{Alumni Perceptions}

Of the alumni, 75\% said GCPs contributed to their career progress; $7.5 \%$ were uncertain of the effect of GCPs as they recently completed the program, and $2.5 \%$ completed the program as career training to start a business Another $2.5 \%$ responded that the immediate impact is unclear but the skills will help in the future. Alumni were asked to rate the agreement level in regards to implementation of the skills acquired through GCPs, the details are shown in Figure 5. 


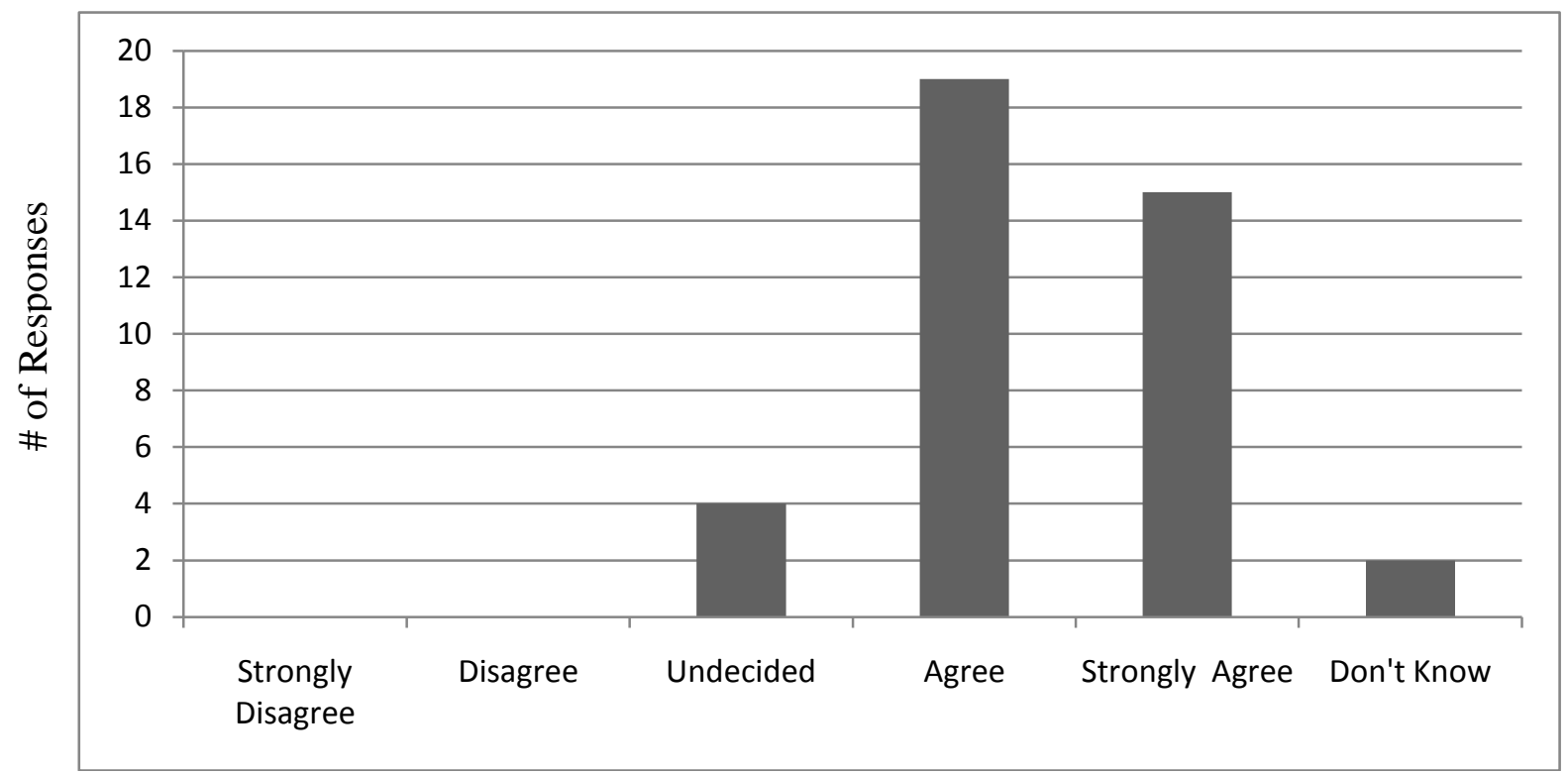

Figure 5. EMSE Graduates' Perception Of Their Ability To Implement The Skills Acquired Through GCP

Figure 6 illustrates a comparison of responses from two groups, students and alumni, when asked how the GCPs will help or has helped them already. In this question participants could select all the options that apply. Eighty-one percent of students and 90\% of alumni have agreed that GCPs have helped in knowledge enhancement, which is positive. There is a discrepancy between the current students' expectations for salary increase and promotions and the benefits that have been experienced by the alumni. This difference may be due to the recent downturn in the economy or a timing issue for recent GCP graduates. Another interesting observation made was that alumni indicated that they were "able to find a job at a desirable location" compared to current students, which could be another results of the downturn in the job market.

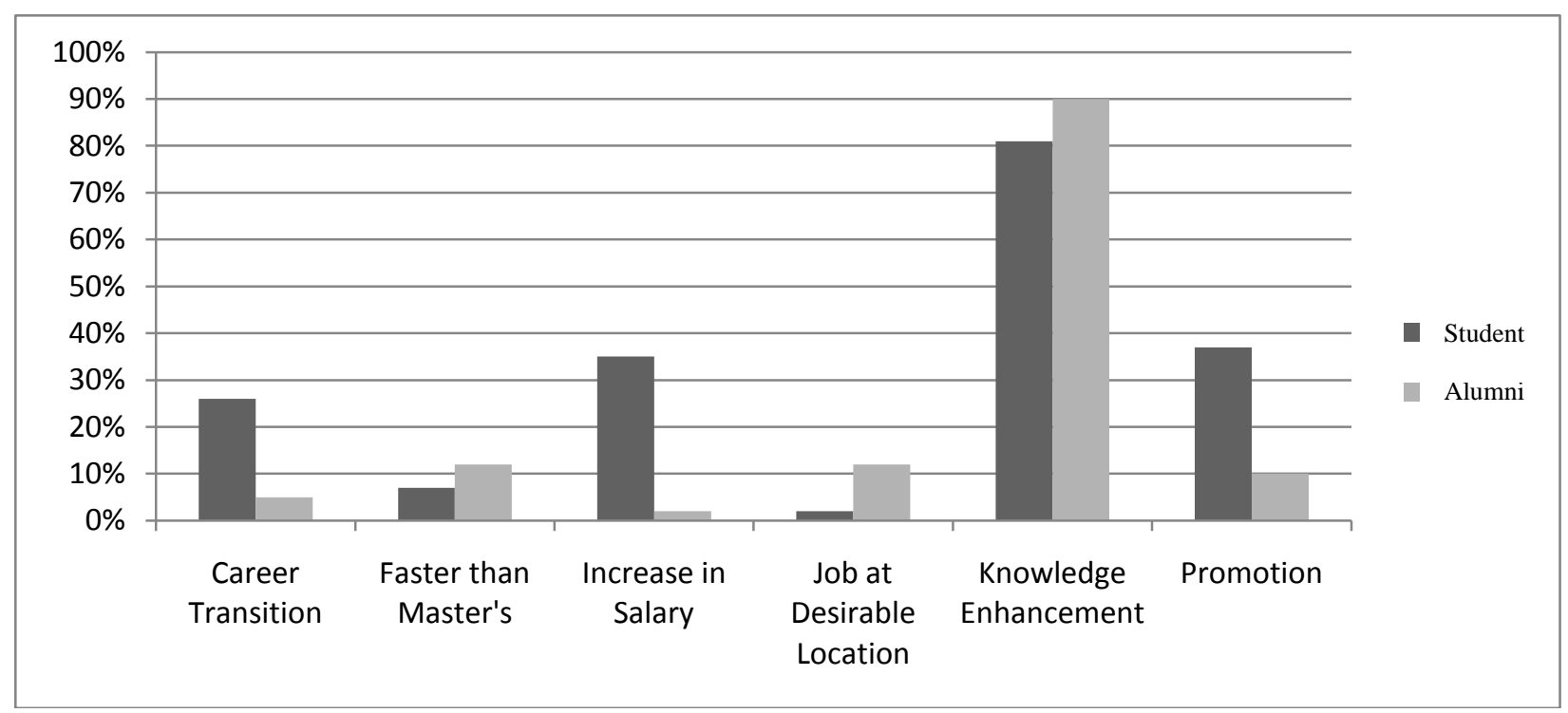

Figure 6. Student Versus Alumni Perceptions Of The Value Of The GCPs 
Alumni were asked qualitative questions to describe in their own words what value the GCP has provided them. Nineteen of the 40 alumni who participated in the survey said that "knowledge and skills enhancement" was the value they obtained from the GCPs. The certificate program aided in advancement of their career, and served as a stepping-stone to continuing in higher education. Four of the alumni stated it helped with their current job. Two wrote that more credibility at the work place is a value of the certificate programs and two said help in future career also as the value from the certificate programs. One of the participants listed the shorter time span of the programs as the value of the GCPs and another said that working while studying was the value of the GCPs.

\section{Industry Perceptions}

Out of 40 industry questionnaire participants, only 22 were aware of the graduate certificate programs offered by Missouri S\&T. This lack of awareness opens up a new opportunity for the university. The industry participants were also asked to identify the skills that are critical for success in their industry. Out of 40 respondents, 38 from different industries stated that soft skills are essential for the success of a new hire. Specific skills identified include: communication, writing, teamwork, ethics, critical thinking, problem solving, leadership, time management, presentation skills, project management, and strategic thinking.

The industry survey participants were also asked: "Are current engineering and engineering management new hires from S\&T well-versed in the skills you identified?" Of the participants, $65 \%$ felt that recruits from S\&T were well-versed in the skill sets required by their industry and $35 \%$ felt that the new hires lack the skills identified by them for professional success in their industry. The questionnaire also asked about preference of employees with Master's degrees compared to GCP graduates. The results are shown in Figure 7. This result, again, highlights an industrial awareness problem concerning GCPs.

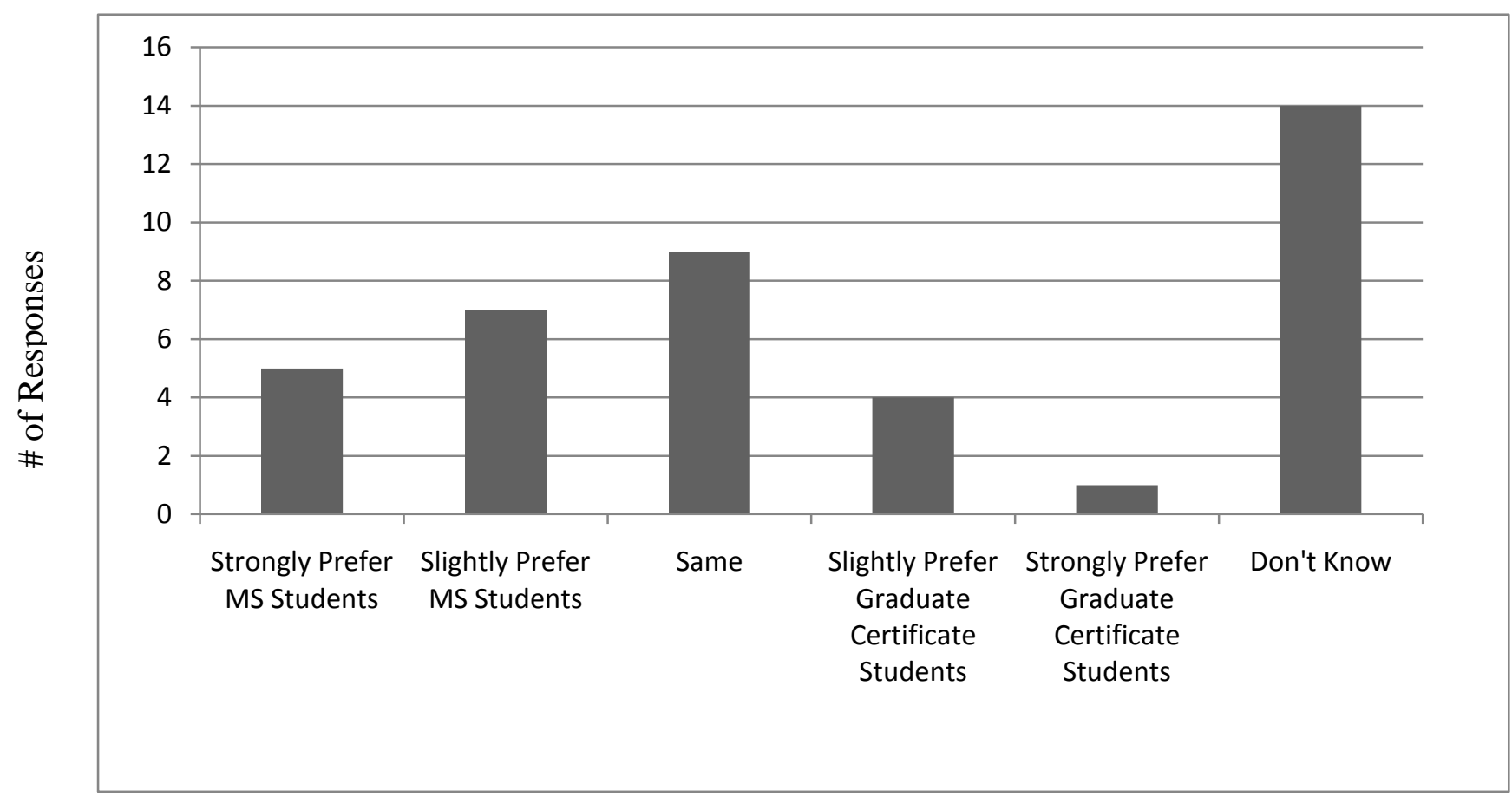

Figure 7. Industry Preference Between Master's And GCP New Hires 


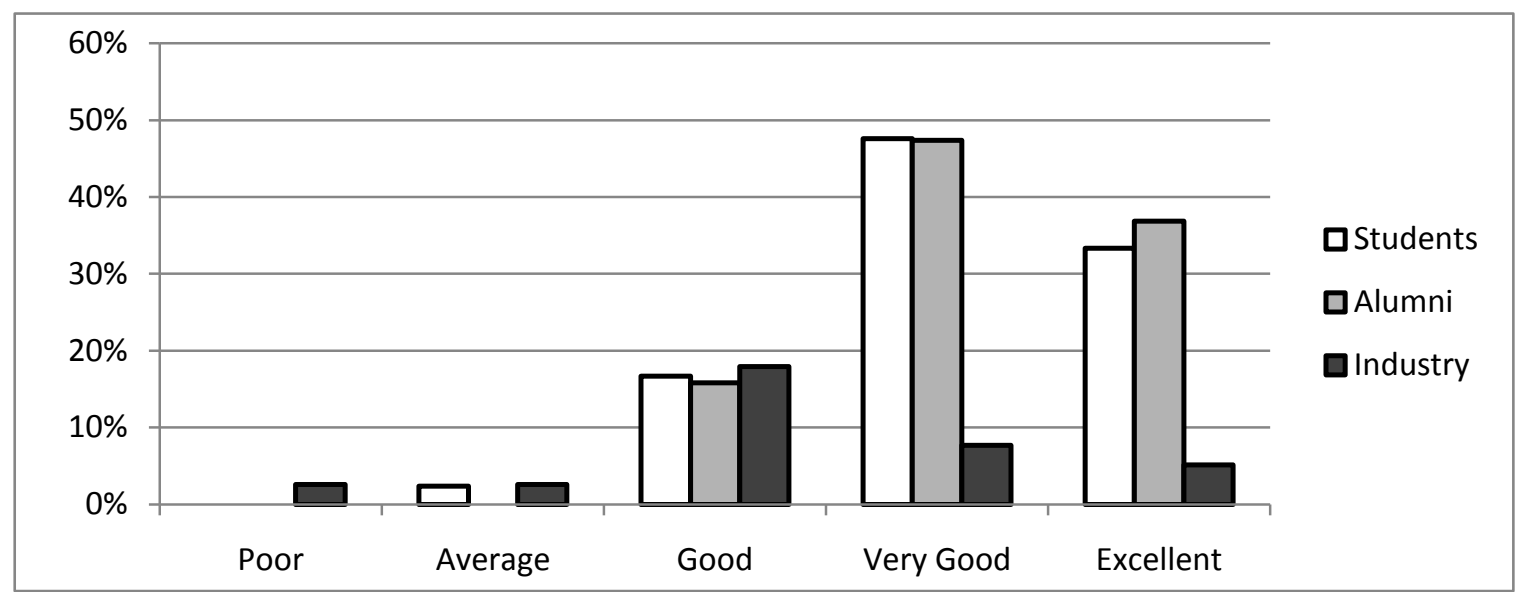

Figure 8. Perceptions Of Value Addition By GCPs

When comparing preference of industry between a Master's degree and GCPs, $12 \%$ said they strongly prefer Master's degrees, $18 \%$ said they slightly prefer Master's degrees over graduate certificates, and $12 \%$ said that they strongly or slightly prefer graduate certificate over Master's degrees. However a significant amount, 22\%, said a graduate certificate and a Master's degree were equivalent. These companies stated they would recruit students with either qualification. One of the significant points to be noted from the industry survey is that $45 \%$ of the participants were not familiar with GPCs. A disconnect that occurs between the facts about an academic department and its markets' perceptions create a less than ideal relationship in understanding, recruiting and hiring the graduates of the program (Elrod 2010). Therefore, it is important for the university to use this opportunity to promote their GCPs heavily to increase industry awareness by educating both students and industry about what CGPs are available, and what their values are.

\section{CONCLUSIONS}

GCPs offer an employee-friendly, but results-oriented system for directing today's employees toward longterm growth and development of the individual and the firm. It can be concluded that collaborations between universities and industry benefit all stakeholders by recruiting students to academia and then placing those students into employment opportunities after completion of either a GCP, or in some cases a Master's degree if the student ventures on in their academic career.

From the analysis of the questionnaire results through chi-square tests performed on the three stakeholders groups: students, alumni and industry, we can clearly see that the three groups do not agree on the value of the GCPs and further chi-square testing shows that the two groups alumni and students agree on the value of the programs but the third group "industry" is not homogeneous with the other two groups regarding the value of the GCPs. In order to ensure a successful cyclical cycle from academia to industry, the industry stakeholder should be educated by the academic stakeholder to understand the value that the certificate program could offer. It was concluded, however, that certificate programs do provide some value for the majority of industry respondents. The results of the case study show that the following three points will enable the GCPs to be more valuable and students more successful:

- Increasing the awareness of the industry on GCPs

- $\quad$ Train the students in soft skills

- $\quad$ Try to provide the students with real world experience either by co-op and internships or by designing projects or programs that would simulate the real world situations

Since nearly all of the students who completed their GCP in the year before this study was conducted went on to pursue a Master's degree, we can conclude that the GCPs are in fact acting as recruiting agents for the graduate programs at the university. This serves as a great value for the academic stakeholder by allowing students 
to start slowly into graduate coursework and then apply it toward a Master's degree. Overall, the study shows that GCPs can be a successful recruiting tool for academia, aid students in preparing for a Master's degree or finding a strong job, and also to industry in finding qualified individuals to employ, despite the downturn in the economic situation.

\section{BIOGRAPHY}

Dr. Susan Murray is an Associate Professor of Engineering Management and Systems Engineering at the Missouri University of Science and Technology (Missouri S\&T). She received her PhD in industrial engineering from Texas A\&M University. Dr. Murray is an expert in human factors, safety engineering, engineering education, and project management. She has received numerous teaching awards. Prior to joining the academia, she worked in the aerospace industry and spent two years at NASA's Kennedy Space Center. Dr. Murray is a Professional Engineer in Texas.

Dr. Suzanna Long is an Assistant Professor in the Department of Engineering Management and Systems Engineering at Missouri University of Science and Technology. She holds a PhD in Engineering Management from the University of Missouri-Rolla (UMR). Her research interests include logistics and technology-driven change management and the application of supply chain theory to sociotechnical systems.

Dr. Cassandra Elrod is an Assistant Professor of Operations Management in the Department of Business and Information Technology at the Missouri University of Science and Technology (formerly University of Missouri Rolla). She received her PhD in Engineering Management from the University of Missouri - Rolla. Dr. Elrod's research interests include quality management, experiential learning, engineering education, marketing management, and project management.

Susmitha Akula holds a BS degree in Mathematics, Physics and Chemistry from Nagarjuna University and a MS in Engineering Management from the Department of Engineering Management and Systems Engineering at Missouri University of Science and Technology. She has prior experience as Assistant Manager Operations at Lakshmi Logistics and Transportation Ltd (LLT).

\section{REFERENCES}

1. Cannon, M. M., \& Umble, K. E., Steckler, S., \& Shay, S. (2001). We're Living What We're Learning: Student Perspectives in Distance Learning Degree and Certificate Programs in Public Health. Journal of Public Health Management and Practice, 49-59.

2. Charlton, R., Machin, S., \& Clough, A. (2000). Collaborating with the consortium: the development of a foundation in critical care skills program. Nursing Critical Care, 5(2), 62-67.

3. Daughton, W. (2007). Graduate certificates as recruiting and entry vehicles. American Society for Engineering Education .

4. Donovan, C. P. (1998). Consider try-it-yourself Certificate Programs. Workforce, 5, 101-104. Retrieved November 1, 2009 from http://www.workforce.com/archive/feature/22/16/52/index.php

5. Dowdy, S. M., \& Wearden, S. (1991). Statistics for research. West Virginia: Wiley-Interscience Publication.

6. Elrod, C. C., Daughton, W. J., Murray, S. L., and Flachsbart, B. B. (2010). Evaluating the Engineering Management Brand Meaning. Engineering Management Journal, 22:2, 16-26.

7. Evans, R. M., Murray, S. L., Daily, M. M., and Hall, R. E. (2000). Effectiveness of An Internet-Based Graduate Engineering Management Course. Journal of Engineering Education,

8. Jaffeson, R. C. (2004). Association certification: Proven Pathway to Professionalism. Corrections Today. Retrieved April 7, 2009 from http://findarticles.com/p/articles/mi_hb6399/is_5_66/ai_n29114484/?tag=content;col1.

9. Kerka, S. (2000). Career certificates: High quality and cutting edge? OH: ERIC Clearinghouse on Adult, Career, and Vocational Education, 16, 1-4.

10. Lohman, E. M. (2003). The relationship between non completers' decisions to leave certificate programs before earning certificate and their career goals. Dissertation Abstracts International, 64 (10A:3575). 
11. Miller, E. N. (2002). Test-retest reliability of alcohol measures: Is there a difference between Internet based assessment and traditional methods? Psychology of Addictive Behaviors, 16, 56-63.

12. National Center for Education Statistics (2006-2007). Distance Education at Degree-Granting Postsecondary Institutions: 2006-2007, US Department of Education, 1-19.

13. Tibbo, H. R. (2006). So much to learn, so little time to learn it: North American archival education programs in the information age and the role for certificate programs. 6, 231-245. 


\section{NOTES}

